\title{
ANALYSIS OF RETURN AND STORAGE OF AUTOMOTIVE BATTERIES IN AN AUTHORIZED DEALER, A PROBLEM OF REVERSE LOGISTICS
}

\author{
${ }^{* 1}$ Natiliane de Jesus Sousa Soares, ${ }^{1}$ Mauro César Aparício de Souza, ${ }^{2}$ Marden Eufrasio \\ dos Santos, and ${ }^{2}$ David Barbosa de Alencar
}

1Academic department, University Center FAMETRO, Amazon-Brazil

2Institute of Technology and Education Galileo of Amazon (ITEGAM), Brazil

\section{ARTICLE INFO}

\section{Article History:}

Received $09^{\text {th }}$ January, 2020

Received in revised form

$17^{\text {th }}$ February, 2020

Accepted $26^{\text {th }}$ March, 2020

Published online $29^{\text {th }}$ April, 2020

\section{Key Words:}

Reverse logistic; Social and Environmental Responsibility; Solid Waste Storage.

*Corresponding author: Natiliane de Jesus

Sousa Soares

\begin{abstract}
Reverse logistics works in order to dispose of batteries to the entire region in order to facilitate the flow of automotive batteries and waste to minimize incorrect disposal. When improperly neglected, the components in the battery, such as lead and sulfuric acid solution, can cause serious problems in the environment, and in humans. The study aimed to analyze the system of reverse logistics and storage of waste batteries within the company, identify the problems that the company faces in relation to the return of scrap and stock, which are interrelated and influence the performance of the reverse logistics system . Data collection was carried out through notebooks, semi-structured interviews directed to the manager of the analyzed company and the employees of the distributor in the region, using FIFO, Pareto Diagram and 8S. The results reveal that the return of useless batteries, collection, socio-environmental responsibility, battery storage, are in need of good management and communication and interconnections in the reverse scrap logistics chain.
\end{abstract}

Copyright (C) 2020, Natiliane de Jesus Sousa Soares et al. This is an open access article distributed under the Creative Commons Attribution License, which permits unrestricted use, distribution, and reproduction in any medium, provided the original work is properly cited.

Citation: Natiliane de Jesus Sousa Soares, Mauro César Aparício de Souza, Marden Eufrasio dos Santos, and David Barbosa de Alencar. "Analysis of return and storage of automotive batteries in an authorized dealer, a problem of reverse logistics”, International Journal of Development Research, 10, (04), 35001-35006.

\section{INTRODUCTION}

Com a falta de estrutura do transporte coletivo de Manaus, tem aumentado a demanda por automóveis privados, do qual consequentemente aumenta o número de baterias usadas, atualmente tem veículos que necessitam de uma bateria específica, geralmente as baterias tem uma vida útil de 18 a 24 meses, ou seja, sempre a necessidade pela sua troca no final da sua vida útil. Conforme a Resolução CONAMA No 257/1999 - "Estabelece que baterias que contenham em suas composições chumbo, cádmio, mercúrio e seus compostos, tenham os procedimentos de reutilização, reciclagem, tratamento ou disposição final ambientalmente adequado". Data da legislação: 30/06/1999 - Publicação DOU n 139, de 22/07/1999, págs. 28-29. Status: Alterada pela Resolução no 263, de 1999. Revogada pela Resolução $n^{\circ} 401$, de 2008. Também tem a finalidade de estabelecer regras sobre a logística reversa. A logística reversa tem por finalidade o processo de mover um bem da sua destinação final até a sua origem, para serem adequadamente descartadas, reaproveitadas para evitar tais agravos ao planeta (EDILSON MENDES NUNES 2015/2016).
Outro órgão atuante na proteção ambiental é o Instituto de proteção Ambiental do Amazonas (IPAAM), que fiscaliza e vistoria o local de armazenagem temporário de resíduos sólidos perigosos, conforme a lei $\mathrm{N}^{\circ} 3.785$ DE JULHO DE 2012. No mundo atual muito se fala em logística reversa, como meio de amenizarmos impactos ambientais, impactos econômicos para as empresas que trabalham diretamente com produtos que requerem uma reciclagem dos seus componentes. Nas empresas a logística não se refere apenas a distribuição física das mercadorias e $\operatorname{sim}$ a gestão de estoque e armazenamento. A logística deve ser aplicada no gerenciamento de resíduos pós consumo, podendo retorná-lo ao ciclo de forma a gerar lucratividade, reduzir custos ou consolidar uma imagem positiva e ambientalmente responsável perante o mercado consumidor (CHAVES E MARTINS , 2005). Toda empresa que trabalha com produtos considerados perigosos, tem que seguir leis para o seu funcionamento, como o licenciamento do IPAAM (Instituto de Proteção Ambiental), armazenar esses resíduos, requer toda uma estrutura adequada para que esses matérias sejam armazenados de forma segura, até que seja feita a coleta de forma apropriada pela empresa 
responsável. Considerando a necessidade de reduzir tanto, quanto possíveis, a geração de resíduos, com a finalidade de minimizar os impactos negativos causados ao meio ambiente pelo descarte inadequado das baterias. Adotando procedimentos técnicos de coleta, recebimento na própria loja para devolver a distribuidora para a embalagem e posteriormente mandar de volta a fábrica, para sua reciclagem de acordo com a legislação vigente da resolução CONOMA ${ }^{\circ}$ 401 de 04/11/2008. A gestão da empresa criou um sistema chamado a base de troca, quando o consumidor compra um novo produto tem desconto deixando a sucata. Esse desconto chega a custar de trinta a cento e dez reais ( $\mathrm{R} \$ 30,00$ a 110,00), dependendo da amperagem da bateria. O objetivo deste trabalho é analisar o regresso das baterias inservíveis, a dificuldade que a empresa enfrenta na organização do estoque, e na demora que o revendedor leva para devolver as sucatas ao distribuidor.

\section{FUNDAMENTAÇÃO TEÓRICA}

Este trabalho trata do inadequado armazenamento de baterias, que são devolvidas pelo consumidor final ao revendedor autorizado. Para isso vai ser utilizado o conceito da logística reversa. Também citaremos as normas vigentes referente a esse tipo de produto, e a ferramenta Diagrama de Pareto para identificar a real situação do estoque em relação ao armazenamento das sucatas e a metodologia do $8 \mathrm{~s}$ para a organização e engajamento dos colaboradores para o objetivo da empresa, que é, manter o estoque mais organizado e transitável, aumentar seu espaço físico e utilizar a filosofia do FIFO para ter agilidade na devolução da sucata.

Logística Reversa: A logística reversa é um planejamento estratégico e eficiente, como um propósito de alcançar os objetivos esperados, visando o retorno das sucatas e componentes importantes como chumbo da bateria, de modo a obter rendimentos em diversos campos de atuação, buscando sempre reciclar seus resíduos, além de reduzir custos e garantir uma boa visibilidade positiva do que é oferecido, pensando nisso a empresa preocupa-se com o destino final do seu produto que é vendido (NOGUEIRA, 2012). Para VITÓRIO DONATO (2008) as empresas estão cada vez mais acompanhando o ciclo de vida de seus produtos. Isto se torna cada vez mais claro quando se observa que a empresa trabalha com o recolhimento dos seus produtos inservíveis, no sentido de minimizar o impacto ambiental, não só dos resíduos na esfera da produção e pós- consumo, mas de todos os impactos ao longo do ciclo de vida dos produtos, já que a logística reversa viabiliza a devolução para a produção, materiais que serão reaproveitados. A logística reversa está sendo levado a sério no Brasil. As empresas sabem que para serem competitivas precisam, além de ter um bom produto, disponibilizá-lo no momento certo conforme a necessidade do cliente. Isso não impede que seus processos possam ser revistos para continuar atendendo as necessidades e obtendo redução de custos, pois quando bem definidos trarão ganhos expressivos para as organizações (NOGUEIRA 2012).

Legislações Ambientais para Logística e Armazenamento de Baterias: A Resolução CONAMA n ${ }^{\circ} 257$, de 30 de junho de 1999. Obriga as empresas fabricantes a receber seus resíduos e dá um destino final e ao revendedor, consumidor final a devolver a sua bateria usada em pontos de coleta autorizado, assim como as que trabalham ou revendem esses produtos a coletar e dar a destinação final, ambientalmente adequada, de acordo com a quantidade que formas adquiridas, tanto em quantidades que são fabricadas, quanto vendidas. Conforme a lei $\mathrm{N}^{\circ} 3.785$ DE JULHO DE 2012, Art. 16 . O Instituto de Proteção Ambiental do Amazonas - IPAAM, mediante ato próprio, definirá os procedimentos específicos para as licenças e autorizações ambientais estaduais, observadas a natureza, características e peculiaridades da atividade ou empreendimento e, ainda, a compatibilização do processo de licenciamento ( IPAAM No 3.785/2012).

Diagrama de Pareto: O gráfico de Pareto é um método gráfico de apresentação de dados por ordem de tamanho, importância ou prioridade. A utilização do gráfico permite identificar com eficiência esses tipos de problemas que afetam grandemente a qualidade do produto ou serviço (RAMOS,2013). O princípio de Pareto afirma também que entre todas as causas de um problema, algumas poucas são as grandes responsáveis pelos efeitos indesejáveis do problema. Logo, se forem identificados as poucas causas vitais dos poucos problemas vitais enfrentados pela empresa, será possível eliminar quase todas as perdas por meio de um pequeno número de ações (CARPINETTI, 2012).

\section{Programa 8S}

Para melhorar o programa 5S, pouco completo. Para torna-lo mais abrangente, foi inserido mais três "S"adicionais (Abrantes, 2007):

Shikariyao: Senso de determinação e união, o objetivo é conseguir a participação direta de todos da direção em conjunto com os funcionários a trabalhar na implementação da filosofia de gestão, deixando de ser usados por níveis hierárquicos.

Shido: Senso de treinamento. Objetiva implantar um programa de treinamento estruturado em todos os níveis organizacionais, aumentando a empregabilidade dos funcionários e fazendo com que todos se sintam importantes para a empesa:

Setsuyaku: Senso de economia e combate aos desperdícios. Objetiva implantar uma etapa que complete todo o ciclo dos $8 \mathrm{~s}$, complementando os outros $5 \mathrm{~s}$. Pode ser considerado o ponto alto do programa, em que os funcionários são convidados a dar sugestões, propor soluções, enfim, a participação ativamente do dia a dia da organização, sendo recompensado com elogios, prêmios e vantagens oferecido pela direção.

Sistema FIFO: Criar uma filosofia de estoque que seja condizente com a atividade fim da empresa, é fundamental para que não haja desperdícios de espaço físico. A adoção da técnica errada de armazenagem pode fazer com que a logística da empresa deixe de agregar valor ao produto/serviço e passe a onerar a atividade em questão. Algumas ferramentas auxiliam as empresas no controle de entrada e saída de materiais, assim como influenciam os custos, podendo ser aplicadas para que o controle de estoque seja mais eficiente (FOCO LOGÍSTICO, 2014). A seguir estão listadas algumas destas ferramentas. FIFO (First in First out - primeiro que entra, primeiro que sai) - faz com que as primeiras sucatas que entra devem ser pesadas e embaladas para devolver ao coletor, tornando-se uma movimentação de resíduos mais ágeis. É essencial que a demanda pelos produtos inservíveis seja vista com tanta importância quantos os novos produtos que chega a empresa, 
necessário um alto grau de precisão, a organização tem um fornecedor de transportes confiável a fim de obter um serviço adequado à demanda (PORTAL EDUCAÇÃO, 2014).

\section{MATERIAIS E MÉTODOS}

Para a realização deste trabalho utilizou-se a pesquisa de análises quantitativas e qualitativas, as quais foram feitas revisões bibliográficas sobre o tema e os assuntos abordados, as ferramentas que serão utilizadas para a realização de levantamentos de dados por meio de análise documental. Houve também uma entrevista com o diretor da empresa e funcionários que trabalham diretamente no setor de armazenamento e logística, a fim de entender como funciona o processo logístico e armazenamento das baterias automotivas, desde que chegam a empresa as novas baterias, até o seu retorno a distribuidora da região. Onde foi confeccionando o fluxograma logístico atual para saber como funciona o sistema da organização deste a venda dos produtos até a solicitação da coleta. Através das ferramentas Diagrama de Pareto e Diagrama de Ishikawa foram identificados os problemas da empresa, e a utilização do FIFO, 5S “organizar”, criação dos fluxogramas de possíveis melhorias para principalmente setores, como de logística e armazenamento de resíduos sólidos.

\section{APLICAÇ̃̃O DO ESTUDO}

Fluxos do Processo Atual: Atualmente a empresa não dispõe de um fluxograma, todas as informações são anotadas em um caderno que serve para saber o que entra e sai da empresa, não possui um fluxo definido para uma linha de segmento onde os colaboradores da empresa possam seguir, geralmente a rotina de trocar e armazenar é a mesma, trocou as baterias em andamento, deixa a sucata no local da troca até surgir um momento de levar para o estoque, não tem um sistema para contabilizar ou informar quantas baterias inservíveis entraram na empresa semanalmente. Na figura 1 , foi feito um fluxo para o entendimento de como funciona o processo atualmente.

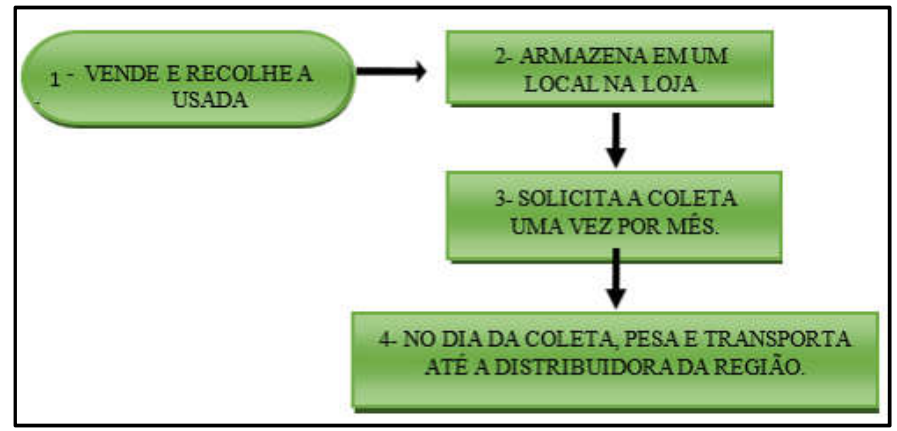

Fonte: Os Autores, 2020

\section{Figura 1. Fluxo do armazenamento atual}

Em relação à logística reversa das baterias automotivas, a empresa não dispõe de divulgação da importância da devolução da sucata. Sobre o armazenamento dos resíduos sólidos, a loja não é autorizada pelo IPAAM, a manter esses produtos no interior da sua loja.

Identificações dos Problemas Atuais : Como a organização não dispõe de um fluxograma, os colaboradores não sabem como agir, não sabem ao certo como se comportar diante de um acumulo de sucatas na frente da loja. Como não tem um fluxo definido a desordem das baterias é grande, a empresa não tem um sistema de gerenciamento e controle das baterias inservíveis, tudo e anotado em papel de orçamento ou cadernos aleatórios, tanto as que vão para recarga quanto as sucatas.

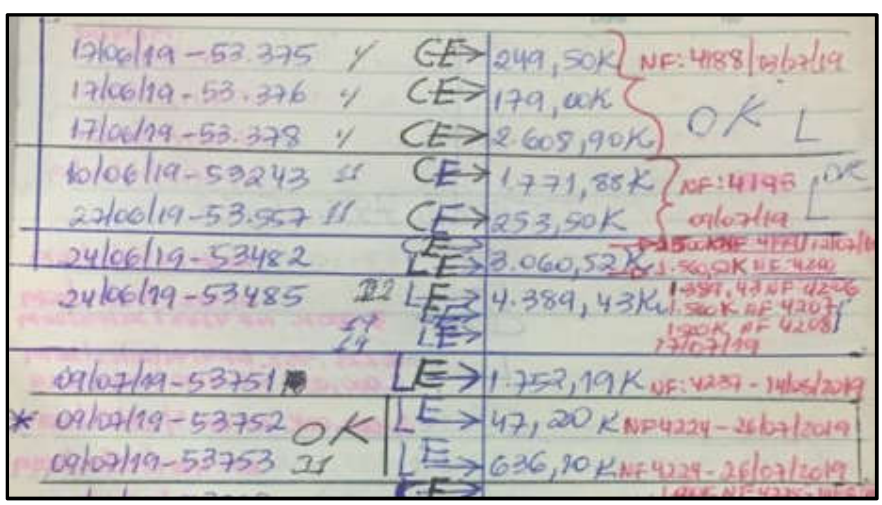

Fonte: Os Autores, 2020

Figura 2. Caderno de Anotações Sucatas

O armazenamento dos resíduos sólidos, não flui com tanta rapidez, ocasionando assim resíduos perigos por muito tempo no interior da empresa. $\mathrm{O}$ gráfico da figura 3, mostra osprincipais problemas da empresa atualmente. A folha de verificação é uma ferramenta usada para analisar a frequência com que certas situações acontecem, com a aplicação verificou que a empresa vinha apresentando um problema no armazenamento de resíduos sólidos, seguindo da desordem de estoque e questão ambiental, considerados perigos a saúde. Como é visto na Tabela 2, o armazenamento das sucatas, ou seja, o estoque de resíduos impróprios, não era separada por amperagem e não é embalada para o transporte e o resíduo sólido demora para ser devolvido para o distribuidor da região.

Tabela 1. Tipos de Problemas Analisados

\begin{tabular}{|l|c|c|c|}
\hline \multicolumn{1}{|c|}{ Problemas } & Total & \% & \% Acum. \\
\hline Armazenagem imprópria & 22 & $28 \%$ & $28 \%$ \\
\hline Desordem estoque & 20 & $25 \%$ & $53 \%$ \\
\hline Questão ambiental & 10 & $13 \%$ & $65 \%$ \\
\hline Sem sistema ERP & 9 & $11 \%$ & $76 \%$ \\
\hline Licenciamento vencido & 8 & $10 \%$ & $86 \%$ \\
\hline Segurança EPI & 6 & $8 \%$ & $94 \%$ \\
\hline Coleta das sucatas & 5 & $6 \%$ & $100 \%$ \\
\hline & 80 & & \\
\hline
\end{tabular}

Fonte: Os Autores, 2020.

Através das informações obtidas da folha de verificação, coletamos os dados para montar o gráfico e priorizar a causa mais relativa. Conforme visto no gráfico 2.1 depois que os dados foram organizados, verificou o percentual de defeito mais constante na empresa, foi a armazenagem impropria e a segurança dos funcionários por falta do uso corretos dos EPIs.

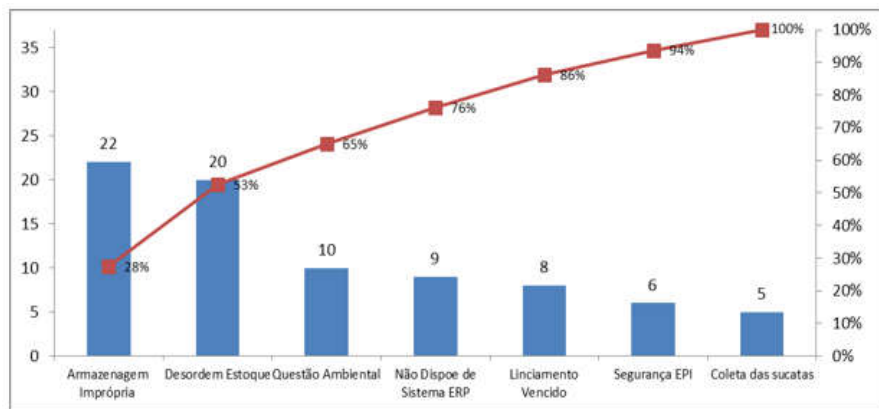

Fonte: Os Autores, 2020

Figura 3. Gráfico de Análise dos problemas utilizando o Diagrama de Pareto 
Para melhorar algum processo e preciso se atentar ao estoque, a logística buscar reduzir custos com armazenagem desnecessários e o estoque tem impacto direto com o lucro da empresa, isso se tornou um problema enorme para a organização, como a empresa não dispõem de um estoque organizado e estruturado, produtos são colocados em qualquer lugar sem cuidado algum. Como passa um rio próximo à loja e em época de chuva ocorrem alagamentos, causando a poluição local e da água.

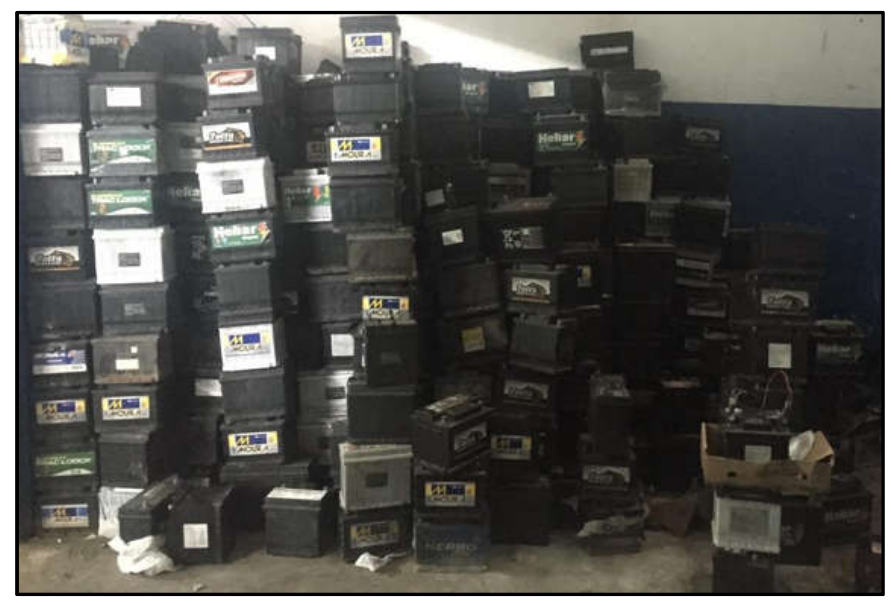

Fonte: Os Autores, 2020.

Figura 4. Armazenagem Inapropriada das Baterias Automotivas

No interior da loja existem, poucas ou quase nenhum panfleto ou cartaz falando sobre a importância da devolução da sucata e da logística reversa, e nem sobre a lei do CONAMA, onde diz que todo consumidor é obrigado a devolver a sucata.

\section{Propostas de Melhorias}

Implantar um sistema ERP (Sistema Integrado de Gestão Empresarial), onde tornaria tudo mais simples, fácil e eficiente, onde o diretor pudesse colocar todas as informações que anota no caderno nesse sistema, como a Figura 4 mostra, criou-se um fluxo definido de como proceder no andamento desde a solicitação das baterias novas até a devolução da sucata para a fabricante, tornando uma logística mais ágil e eficiente. Tornando viável a tomada de decisão quando necessária e solicitar a coleta três vezes ao mês ou mais de acordo com a demanda. Como foi citado no item de identificação dos problemas, a empresa não possuía o licenciamento para armazenar resíduos sólidos no interior da sua empresa. $O$ gestor da empresa junto com órgão responsável pela empresa conseguiu um licenciamento para a armazenagem temporariamente dos resíduos, assegurado pela lei $\mathrm{N}^{\circ} 3.785$ DE JULHO DE 2012, Art. 16 , tornando a empresa apta a recolher e armazenar esses resíduos temporariamente, como mostra a figura 6 , licenciamento de armazenamento de baterias. Para que uma empresa tenha um aumento na sua lucratividade é importante uma boa administração do estoque, quanto menos tempo o produto ficar no estoque melhor. Com isso foi implantado o $5 \mathrm{~S}$ para criar um estoque mais organizado e padronizado. A adoção e implementação dos critérios estabelecidos no programa $5 \mathrm{~S}$ possibilitam a consecução de relevantes resultados (CARVALHO, 2011 pg.64).

-A melhor na utilização dos espaços físicos da empresa e a disponibilização de melhores opções para a ocupação destes;
- $\quad$ O fortalecimento dos aspectos concernentes à imagem e da organização tanto para os funcionários como para os clientes.

Como mostra a figura 7, armazenamento adequado das baterias em local seguro e protegido.

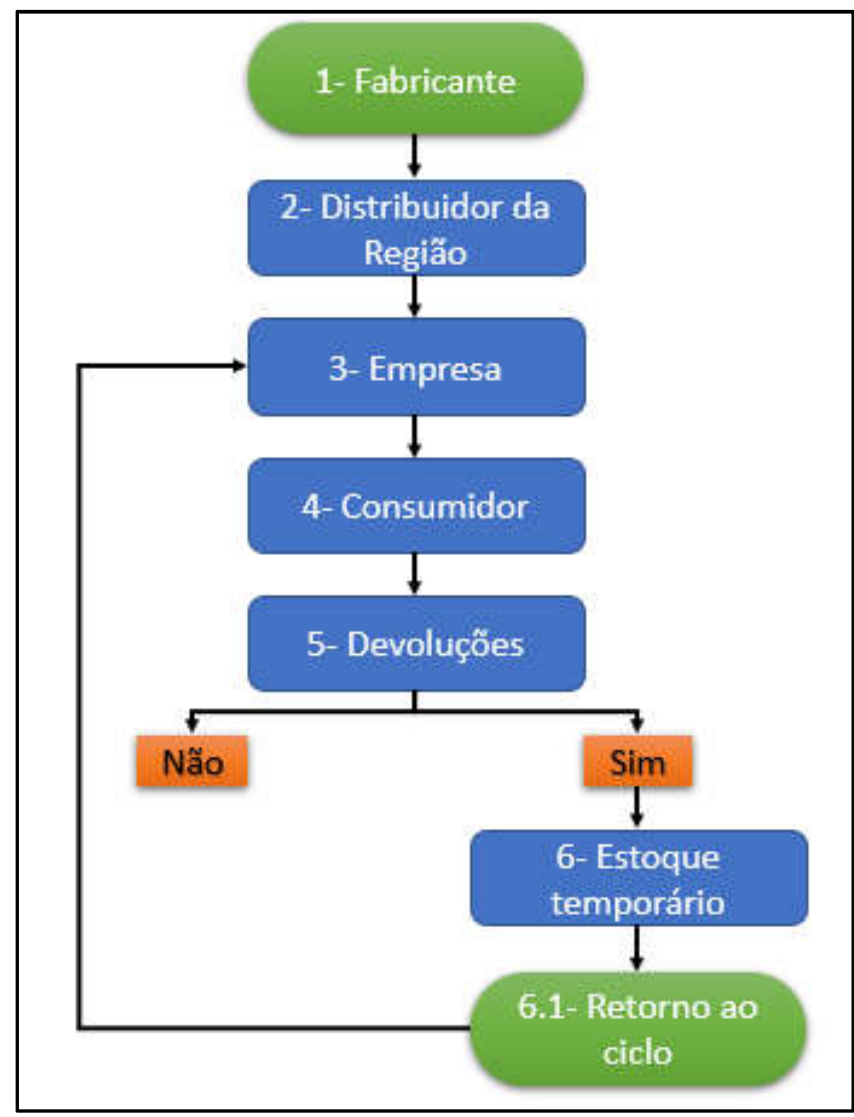

Fonte: Os Autores, 2020.

Figura 5. Fluxo de Melhoria das Baterias Automotivas Externo

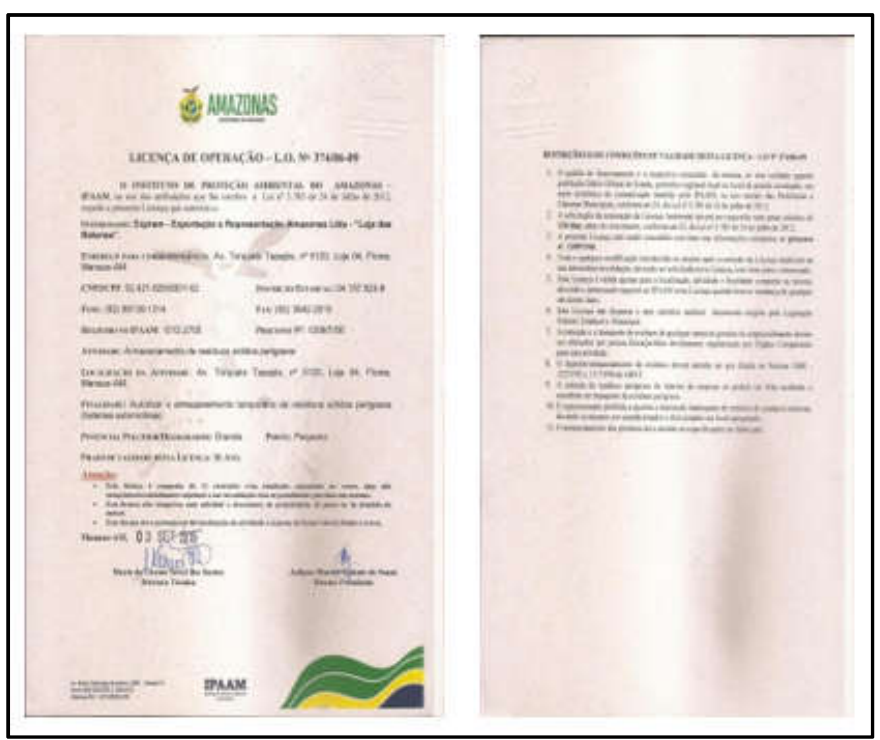

Fonte: Os Autores, 2020.

Figura 6. Licenciamento para armazenar baterias temporariamente

Em relação a panfletos a empresa fez uma solicitação para a distribuidora da região, para vim até a loja e distribuir e colocar no interior da empresa, no balcão, para mostrar e incentivar todos os colaboradores a devolver a sucata para voltar à logística, tornando reversa e sustentável. 


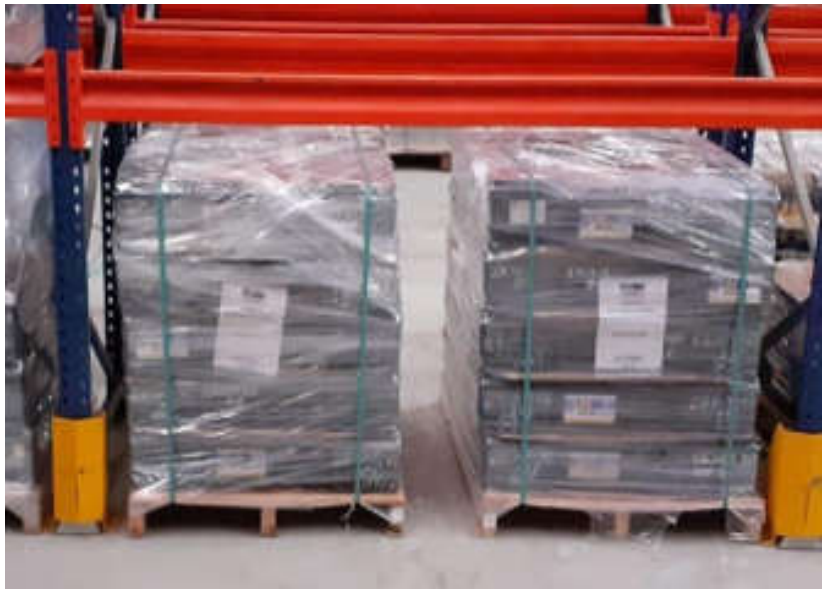

Fonte: Os Autores, 2020.

Figura 7. Armazenagem de baterias automotives

\section{RESULTADO E DISCUSSÕES}

Após a análise de vários problemas, a diretoria da empresa optou por mudanças que pudesse melhorar seus serviços, com isso resolveu organizar seu estoque, melhorar alguns quesitos, procurou firma uma parceria com a fabricante dos produtos carro chefe da sua empresa para a divulgação e transporte necessário para faze sua organização mais ágil e funcional. Investiu em treinamentos para os funcionários, onde pudessem adquirir conhecimentos da nova mudança e a importância do uso dos EPIs. Com relação ao armazenamento a responsabilidade tornou-se de todos os colaboradores a separar por amperagem e tamanho e colocar em palhetes para no final embalar e estocar de forma ordenada e correta seguindo um organograma da empresa. A logística reversa serve para fazer com que todas as sucatas devolvidas na frente da loja retorne a fabricante, com isso a participação da empresa e distribuidor da região pela divulgação e panfletagem sobre a importância do descarte correto das baterias automotivas, fazendo com que todos os clientes da empresa possa ter um responsabilidade social ambiental. A empresa tem um ponto de coleta localizado na compensa, com esse ponto de coleta, eles compram baterias de todas as marcas e todos os tamanhos. Quando adquirir novas, devolvam as sucatas, se a empresa compra uma tonelada de bateria nova, tem que devolver a mesma quantidade em sucatas. Usando esse valor, o empresário compra sucatas, para devolver na hora de adquirir na compra das novas baterias. Com a implantação do sistema a "base de troca" que é quando o cliente recebe um valor em reais na devolução da sucata, houve um aumento de mais de $95 \%$ na devolução da sucata.

\section{Considerações Finais}

Este trabalho apresentou uma análise na logística reversa de baterias automotivas, destacando a deficiência no armazenamento correto e regresso das sucatas para a empresa, para que possam ser reciclados seus resíduos, onde os principais são: o chumbo e o plástico. Também foi analisado a falta de estrutura para a armazenagem temporária das baterias inservíveis. Com o novo sistema que a empresa criou, a empresa conseguiu melhor o fluxo das sucatas no seu estoque, o espaço físico ficou melhor para o transporte de carrinhos e empilhadeiras. A organização das baterias e feita em palhetes de 40 toneladas cada e a solicitação da coleta é feita três vezes ao mês, ou mais de acordo com a demanda.
Conforme utilizado a metodologia FIFO, as primeiras baterias que entra na empresa, são as primeiras a ser devolvida ao fabricante. Com isso cada vez que a empresa queira adquirir novas baterias, manda a mesma quantidade em sucatas embaladas. Como nem sempre o cliente tem a bateria usada para deixar, o produto é comprado no valor bruto do produto, quando o cliente faz a devolução no momento da compra da nova bateria, o cliente ganho um desconto no valor da nova, ou quando o cliente vende a sucata, é pago um valor considerável na sucata, dependendo da amperagem o valor pode chegar a $\mathrm{R} \$ 100,00$. Sobre a estrutura foi criado um local com uma estrutura adequada, com calhas adequadas, seguindo as normas do Instituto de Proteção Ambiental (IPAAM), licenciamento para a armazenagem temporária dos resíduos sólidos. A qualidade em serviços e negócios requer planejamentos, estratégias para possibilitar a sobrevivência da empresa, tudo que é desenvolvido dentro de uma organização exigi um direcionamento a qualidade, garantindo a satisfação dos seus clientes. A empresa buscou melhorar seu estoque para torna-se mais competitiva perante a concorrência.

\section{Agradecimentos}

Inicialmente agradeço a Deus por proporciona-me a viver esse sonho, à meus amigos e colegas de graduação, que me dar apoio neste caminho longo, em especial ao professor, metre e Doutor David Barbosa de Alencar, pela orientação do caminho certo para a execução deste trabalho, ao professor Mauro César Aparício , por sempre me dar apoio, pela ajuda em encontrar os melhores livros para embasar no meu tema proposto, é com palavras sabias me mostrou caminho certo a seguir, a amigos e galegas de trabalho que me deram força no meus estudos. Agradeço em especial a minha família, meu avô que viveu esse sonho comigo, hoje estando no céu, sei que está cheio de orgulho e torcendo por mim. Obrigado a todos que de alguma forma contribuíram para este trabalho, obrigado a Deus, por mais um sonho que era distante e agora está se realizando, Obrigado.

\section{REFERÊNCIA}

BALLOU, Ronald H. Gerenciamento da Cadeia de Suprimentos: Logística Empresarial . Bookman Editora, 2009.

BARTHOLOMEU, Daniela Bacchi; CAIXETA FILHO, José Vicente. Logística ambiental de resíduos sólidos. 2011.

BECHARA, Erika. Aspectos Relevantes Da Política Nacional de Resíduos Sólidos Lei Nð 12.305/2010. Editora Atlas AS, 2000.

CARPINETTI, Luiz Cesar Ribeiro. Gestão da qualidade. São Paulo-Atlas, 2012.

CARVALHO, MM de et al. Gestão da qualidade. Teoria e casos, v. 2, 2012.

CARVALHO, Pedro Carlos de. O programa $5 \mathrm{~S}$ e a qualidade total. Campinas: Alínea, 2006.

Conselho Nacional do Meio Ambiente - CONAMA. Disponivel em; < http://www2.mma.gov.br/port/ conama/>Acesso em 28.10.19.

Da Silva Coelho, G. V., \& Pinheiro, A. A LOGÍSTICA REVERSA DE BATERIAS AUTOMOTIVAS: ESTUDO DE CASO DA COMERCIALIZAÇÃO E DESTINAÇÃO FINAL NA CIDADE DE SANTARÉM-PARÁ.

DONATO, Vitorio; VERDE, Logística. Uma abordagem sócio-ambiental. Rio de Janeiro, Editora Ciência Moderna, 2008. 
FOCO LOGÍSTICO. UOL Blog. Em busca da melhor filosofia de estocagem. Disponível em: https://logisticaemfooco. blogspot.com/2014/11/logistica-em-foco-armazenagem. Acesso em: 28.11.2019

Instituto de Proteção Ambiental do Amazonas - IPAAM. Disponível em: http://www.ipaam.br/legislacao. html $>$ Acesso em 28.10.19.

MENDES, Henrique Manoel Riani; RUIZ, Mauro Silva; DE FARIA, Ana Cristina. Logística Reversa de Pilhas e Baterias: Revisão e Análise de um Sistema Implementado no Brasil. Revista em Gestão, Inovação e Sustentabilidade, v. 2, n. 1, 2016.

NOGUEIRA, Amarildo de Souza. Logística Empresarial: uma visão local com pensamentos globalizado. São Paulo: Atlas, p.82,2012.

PACE, João Henrique. O kanban na prática. Rio de Janeiro: qualitymark, 2003

PORTAL EDUCAÇÃO. Estoques - Método Fifo. Disponível em: <https://www.portaleducacao.com.br/ conteudo/artigos/iniciacao-profissional/estoques-metodofifo $>$. Acesso em: 28.11.2019.
RAMOS, Edson MLS; DE ALMEIDA, Silvia dos Santos; DOS REIS ARAÚJO, Adrilayne. Controle estatístico da qualidade. Bookman, 2013.

SALGADO, Tarcísio Tito. Logística: práticas, técnicas e processos de melhorias. São Paulo: Ed. Senac São Paulo, 2014.

SLACK, Nigel et al. Administração da produção. São Paulo: Atlas, 2009.

SOUSA, JV de O., and STÊNIO LIMA RODRIGUES. "Logística reversa de baterias automotivas: estudo de caso em uma rede autocentros do Estado do Piauí." Anais Encontro Internacional sobre Gestão Empresarial e Meio Ambiente 16 (2014).

VALLE, Rogerio; SOUZA, Ricardo Gabbay. Logística Reversa: processo a processo. São Paulo: Atlas, p. 11-36, 2014. 